\title{
Reseña del libro Entornos Personales de Aprendizaje: claves para el ecosistema educativo en red
}

Departamento de Formación y Actualización Académica

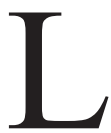

inda Castañeda y Jordi Adell son los editores de la primera publicación del libro digital centrado en el Entorno Personal de Aprendizaje -PLE por sus siglas en inglés-, el cual es definido por los autores como "el conjunto de herramientas, fuentes de información, conexiones y actividades que cada persona utiliza de forma asidua para aprender" (2013, p. 16). Asimismo, consideran al entorno como un "entramado de conexiones sociales y de fuentes básicas" (Castañeda y Adell, 2013, p. 11), inherentes a la construcción del propio aprendizaje.

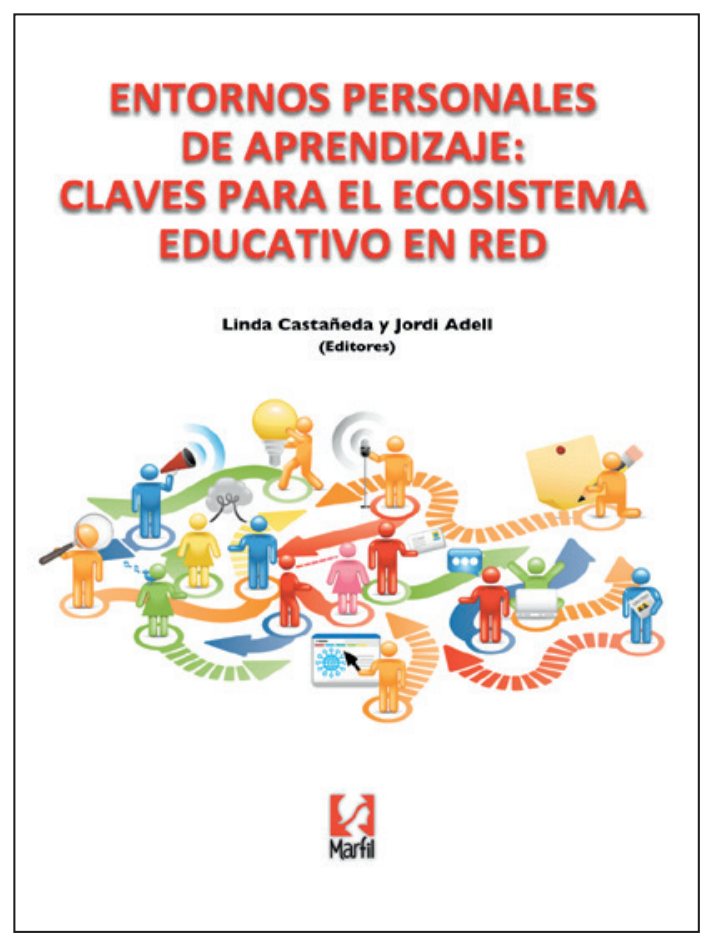

Linda Castañeda y Jordi Adell. (2013).

Entornos Personales de Aprendizaje: claves para el ecosistema educativo en red. España: Marfil. 
El libro está dividido en siete capítulos, con diferentes autores cada uno, enfocados a explicar claramente los elementos que contribuyen al fortalecimiento y aprovechamiento del PLE.

El capítulo uno está centrado en explicar el concepto y los componentes, así como a indagar sobre cómo y cuándo surge el PLE.

El segundo capítulo es una parte central del libro, pues explica el concepto de ecosistema pedagógico o educativo, haciendo referencia a las teorías que sustentan y fortalecen el PLE: conectivismo o conocimiento en las redes; teoría de la complejidad y del aprendizaje emergente, este último caracterizado por ser "abierto y flexible, [y que surge] en los contextos en los que el cambio es rápido e impredecible, es decir, en una sociedad como la actual" (Castañeda y Adell, 2013, p. 35); heutagogía o teoría del aprendiz libre; teoría Laan y finalmente una revisión sobre el constructivismo en el PLE. La relación entre la educación flexible y su aporte al PLE, es explicada en el tercer capítulo por el autor Jesús Salinas.

Oskar Casquero, en el capítulo cuatro, aborda una parte central del PLE, un elemento que es casi inherente al enfoque: la perspectiva tecnológica. Gracias a las TIC es posible no sólo acceder fácilmente a una gran cantidad de datos, sino que éstos pueden debatirse y compartirse con muchas otras personas, creando a su vez más conexiones y aportando al PLE de más estudiantes (2013); sin embargo, es importante aclarar que éste no es tecnología en sí, sino "un enfoque sobre cómo podemos emplear la tecnología actual para enseñar y, sobre todo, aprender" (2013, p. 32).

El capítulo cinco y seis se centran en la planificación del PLE, en el punto de partida, pero también en los obstáculos que podrán presentarse durante su gestión, así como las estrategias para convertir al enfoque en una práctica de vida.
«El libro plantea un enfoque que

complementaría a cualquier metodología

de enseñanza y aprendizaje activa, es

fácil de implementar en todos los niveles

educativos, especialmente en educación

media superior y superior $\gg$

El último capítulo, el número siete, se encuentra dividido en secciones, cada una con testimonios de aplicación del PLE en cada tipo educativo, desde educación básica hasta superior, sin olvidar la formación de docentes en el tema.

Finalmente, es importante destacar que el libro plantea un enfoque que complementaría a cualquier metodología de enseñanza y aprendizaje activa, es fácil de implementar en todos los niveles educativos, especialmente en educación media superior y superior. Los autores, comprometidos y confiados en la utilidad pedagógica del PLE, realizan una invitación a que los docentes y alumnos descubran las herramientas, recursos y relaciones sociales que fomentan la construcción de su propio aprendizaje.

Linda Castañeda y Jordi Adell, con la creación del libro, han realizado un ejercicio de diseño de un PLE, pues desarrollaron varias investigaciones reflexionando en diversos foros sobre el enfoque y su importancia para finalmente compartir el resultado de forma libre a cualquier persona; este último paso es de hecho la culminación de un PLE, el establecimiento de redes para compartir el aprendizaje, por esta razón el libro Entornos Personales de Aprendizaje: claves para el ecosistema educativo en red, bajo una licencia Creative Commons, que fomenta su uso y libre distribución para fines educativos, se encuentra disponible para su descarga gratuita en la página oficial de la Universidad de Murcia: http://www.um.es/ple/libro.

\section{Fuentes de consulta}

Castañeda, L. y Adell, J. (2013). Entornos Personales de Aprendizaje: claves para el ecosistema educativo en red. Alcoy: Marfil. 